\section{(C) OPEN ACCESS}

\title{
Sinonasal adenocarcinoma following styrene exposure in the reinforced plastics industry
}

\author{
Mette Schou Nissen, ${ }^{1}$ Zara Ann Stokholm, ${ }^{1}$ Mette Skovgaard Christensen, ${ }^{1}$ \\ Vivi Schlünssen, ${ }^{2,3}$ Jesper Medom Vestergaard, ${ }^{1}$ Inge Brosbøl Iversen, ${ }^{1}$ \\ Henrik Albert Kolstad'
}

\begin{abstract}
- Additional material is published online only. To view please visit the journal online (http://dx.doi.org/10.1136/ oemed-2017-104974).

${ }^{1}$ Department of Occupational Medicine, Danish Ramazzini Centre, Aarhus University Hospital, Aarhus, Denmark ${ }^{2}$ Department of Public Health, Danish Ramazzini Centre, Aarhus University, Aarhus, Denmark

${ }^{3}$ National Research Centre for the Working Environment, Copenhagen, Denmark
\end{abstract}

Correspondence to Dr Henrik Albert Kolstad, Department of Occupational Medicine, Danish Ramazzini Centre, Aarhus University Hospital, Aarhus 8000, Denmark; henkol@rm.dk

Received 19 December 2017 Revised 6 February 2018 Accepted 17 February 2018 Published Online First 14 March 2018
Check for updates

To cite: Nissen MS, Stokholm ZA, Christensen MS et al. Occup Environ Med 2018:75:412-414.

\section{ABSTRACT}

Background Sinonasal adenocarcinoma is a rare disease expected to have rare causes and potential for strong risk factors as reflected by the strong association with occupational wood dust exposure. High level styrene exposure is a rare and suspected carcinogen, and this study examines the exposure-response relation between occupational styrene exposure, sinonasal adenocarcinoma and other subtypes.

Methods We followed 73092 styrene-exposed workers from 1968 to 2011 and identified sinonasal cancers in the Danish Cancer Registry. We modelled cumulative styrene exposure and estimated incidence rates and age, sex and wood-industry adjusted ORs.

Results During 1585772 person-years, we observed nine cases of adenocarcinoma, corresponding to a fivefold non-significantly increased OR for estimates of high versus low cumulative styrene exposure (OR $5.11,95 \% \mathrm{Cl} 0.58$ to 45.12$)$. The increased risk was confined to exposure received during the recent 15 years. The other histological subtypes showed no increased risk.

Conclusion This study suggests increased risk of sinonasal adenocarcinoma following styrene exposure. The observations are, however, few, confounding from wood dust exposure cannot be ruled out, and additional studies are needed before firm conclusions can be drawn.

\section{INTRODUCTION}

Fifty years ago, Esme Hadfield, an alert ear-noseand-throat clinician, observed a cluster of sinonasal adenocarcinomas among furniture makers in Buckinghamshire, UK, exposed to high levels of wood dust. ${ }^{1}$ Later, several epidemiological studies have confirmed these observations by showing a 10 -fold to 40 -fold increased risk of sinonasal adenocarcinoma following wood dust exposure and today the International Agency for Research on Cancer (IARC) considers the association well established. ${ }^{23}$ Sinonasal adenocarcinoma is a rare cancer and these findings add to similar observations of other rare cancers strongly associated with specific and rare occupational exposures like soot and scrotal cancer and vinyl chloride and angiosarcoma of the liver. ${ }^{4}$ They all provided early and strong signals of carcinogenesis probably because rare diseases according to a deterministic approach to causality are expected to have rare causes and thus potential for large effect measures. ${ }^{6}$

\section{Key messages}

What is already known about this subject?

- Sinonasal adenocarcinoma is a rare disease expected to have rare causes and potential for strong risk factors as reflected by the strong association with occupational wood dust exposure.

What are the new findings?

- High-level occupational styrene exposure is rare and we observed nine cases and a fivefold, non-significantly increased risk of sinonasal adenocarcinoma following high-level cumulative styrene exposure among 73000 reinforced plastics workers.

How might this impact on policy or clinical practice in the foreseeable future?

- This finding may contribute together with other epidemiological, animal and mechanistic data to the assessment of the human carcinogenicity of styrene.

We recently suggested an increased risk of sinonasal cancer among reinforced plastics workers exposed to styrene. ${ }^{7}$ Styrene is classified as possibly carcinogenic to humans by IARC and was listed in the National Toxicology Programme 12th Report on Carcinogens as reasonably anticipated to be a human carcinogen. ${ }^{8}$ High-level styrene exposure occurs almost exclusively among a small number of reinforced plastic workers. We here add to our recent findings by examining the exposure-response relation between quantitative measures of cumulative occupational styrene exposure and sinonasal adenocarcinoma and other histological subtypes.

\section{METHODS}

The study population was 73092 workers that according to a national pension register of all employees in Denmark were ever employed from 1964 to 2007 in 456 small-sized and medium-sized companies producing reinforced plastics. The register provided annual information on employment in these companies and any other company since 1964. Statistics Denmark provided information on occupation 1970-2007. In the National Danish Cancer Registry, we identified all incident cases of sinonasal cancer classified by the 
International Classification of Diseases revision 7 (ICD-7) code 160 (1968-1977) and ICD-10 codes C30 and C31 (1978-2011). According to the morphology codes of the ICD for Oncology, third edition, we defined squamous cell carcinomas (8070/3, $8071 / 3)$, adenocarcinomas $(8140 / 3,8440 / 3,8260 / 3)$ and other histological subtypes $(8002 / 3,8020 / 3,8200 / 3,8430 / 3,8720 / 3$, 9680/3, 9999/3).

We modelled styrene exposure intensity from 1122 personal styrene measurements and company characteristics (production process, product and decade) obtained from 133 reinforced plastics companies 1970-2011. We modelled styrene exposure probability in regression models based on survey exposure information from 11264 present and former employees of all companies linked with information on occupation, sex, product, production process, company size and calendar year available for the complete population. For each worker and each year of employment during styrene production in any of the study companies, we computed a styrene exposure score as the product of predicted styrene exposure probability and predicted styrene exposure intensity. These scores were added across all years of employment to obtain a cumulative styrene exposure score that was categorised into low and high based on the person-year median. We refrained from categorising into tertiles (or more categories) since no case of adenocarcinoma occurred in the median category. We also estimated the three components thereof: duration of employment during styrene production, mean styrene exposure intensity and mean styrene exposure probability. Detailed information on the study population and exposure assessment is described elsewhere. ${ }^{9}$

The study population was followed from 1968 or from 1 January following the year of first employment during styrene production until an incident diagnosis of sinonasal cancer, death, emigration, disappearance or end of follow-up by 31 December 2011, whichever came first.

In the initial analyses, we computed the incidence rates (IR) and estimated crude incidence rate ratios (IRR) with $95 \%$ CI by cumulative styrene exposure score with a discrete survival function. To account for age, sex and wood dust exposure and due to the small number of cases, we then conducted a case-control study nested within the study population. We randomly selected 10 controls for each case by incidence density sampling, matched on age (within 2 years), sex and employment in a reinforced plastics company producing boats or employment in wood industry (sawmilling and planning of wood, manufacture of veneer boards and wood-based boards, manufacture of builders' carpentry and joinery, manufacture of wooden packaging, furniture industry, carpentry and joinery business) since 1964 (never, ever or unknown). With conditional logistic regression, we estimated adjusted OR with 95\% CI by cumulative styrene exposure score and the other exposure metrics accrued during the full work history and during specified time windows $(<15$ years prior, 15-29 years prior and $\geq 30$ years prior). We estimated the log-linear relation with the original continuous variables. Analyses were performed with STATA V. 13.1.

In accordance with the data confidentiality policy of Statistics Denmark, no less than four cases per cell were reported or should be inferred, and for that reason, we only present the overall number of cases from each histological subcategory.

\section{RESULTS}

During the 1585772 accumulated person-years, we identified 37 sinonasal cancers: nine adenocarcinomas, 15 squamous cell carcinomas, 13 other histological subtypes and 370 controls, 10 for each case.

We observed one case of adenocarcinoma per 100000 personyears for a high cumulative styrene exposure score $\left(\geq 37 \mathrm{mg} / \mathrm{m}^{3}\right.$ years, online Supplementary table 1). This corresponded to an eightfold increased crude risk (IRR 8.00, 95\% CI 1.00 to 63.97). No increased risk was seen for squamous cell carcinomas or the other histological subtype category. The age, sex and wood industry matched analyses showed a fivefold increased OR of

Table 1 ORs with $95 \% \mathrm{Cl}$ of sinonasal adenocarcinoma, squamous cell carcinoma and a category of other histological subtypes by styrene exposure in the Danish reinforced plastics industry, 1968-2011*

\begin{tabular}{|c|c|c|c|c|c|c|}
\hline \multirow[b]{2}{*}{ Exposure metric } & \multicolumn{2}{|c|}{ Adenocarcinoma $(n=9)$} & \multicolumn{2}{|c|}{ Squamous cell carcinoma $(n=15)$} & \multicolumn{2}{|c|}{ Other histological subtypes $(n=13)$} \\
\hline & ORt $(95 \% \mathrm{Cl})$ & OR‡ $(95 \% \mathrm{Cl})$ & ORt $(95 \% \mathrm{Cl})$ & OR‡ $(95 \% \mathrm{Cl})$ & ORt $(95 \% \mathrm{Cl})$ & OR‡ $(95 \% \mathrm{Cl})$ \\
\hline \multicolumn{7}{|c|}{ Cumulative styrene exposure score } \\
\hline$<37 \mathrm{mg} / \mathrm{m}^{3}$-years & 1.00 (reference) & 1.00 (reference) & 1.00 (reference) & 1.00 (reference) & 1.00 (reference) & 1.00 (reference) \\
\hline$\geq 37 \mathrm{mg} / \mathrm{m}^{3}$-years & $4.02(0.44$ to 36.6$)$ & 5.11 (0.58 to 45.12$)$ & $1.30(0.37$ to 4.57$)$ & $1.15(0.34$ to 3.89$)$ & $0.88(0.28$ to 2.80$)$ & $0.74(0.22$ to 2.42$)$ \\
\hline Per $100 \mathrm{mg} / \mathrm{m}^{3}$-years & 1.36 (1.09 to 1.68$)$ & $1.08(0.96$ to 1.21$)$ & 0.96 (0.81 to 1.14$)$ & $1.02(0.83$ to 1.25$)$ & $0.80(0.51$ to 1.20 & $0.75(0.46$ to 1.23$)$ \\
\hline \multicolumn{7}{|c|}{ Mean styrene exposure intensity } \\
\hline$<23 \mathrm{mg} / \mathrm{m}^{3}$ & 1.00 (reference) & 1.00 (reference) & 1.00 (reference) & 1.00 (reference) & 1.00 (reference) & 1.00 (reference) \\
\hline$\geq 23 \mathrm{mg} / \mathrm{m}^{3}$ & $1.85(0.34$ to 10.20$)$ & $2.06(0.38$ to 11.25$)$ & $0.45(0.14$ to 1.47$)$ & $0.43(0.14$ to 1.32$)$ & $0.46(0.14$ to 1.51$)$ & $0.45(0.13$ to 1.53$)$ \\
\hline Per $10 \mathrm{mg} / \mathrm{m}^{3}$ & $1.17(1.04$ to 1.32$)$ & $1.08(0.98$ to 1.18$)$ & $0.99(0.87$ to 1.12$)$ & $0.98(0.86$ to 1.11$)$ & $0.97(0.87$ to 1.09$)$ & $0.95(0.84$ to 1.07$)$ \\
\hline \multicolumn{7}{|c|}{ Mean styrene exposure probability } \\
\hline$<37 \%$ & 1.00 (reference) & 1.00 (reference) & 1.00 (reference) & 1.00 (reference) & 1.00 (reference) & 1.00 (reference) \\
\hline$\geq 37 \%$ & $2.08(0.49$ to 8.85$)$ & $1.81(0.39$ to 8.45$)$ & $1.22(0.41$ to 3.62$)$ & $1.40(0.47$ to 4.20$)$ & $1.45(0.46$ to 4.57$)$ & $0.94(0.29$ to 3.04$)$ \\
\hline Per \% & $1.02(0.99$ to 1.05$)$ & $1.02(0.99$ to 1.05$)$ & $1.00(0.98$ to 1.02$)$ & $1.00(0.98$ to 1.02$)$ & $1.00(0.98$ to 1.02$)$ & 0.99 (0.97 to 1.01$)$ \\
\hline \multicolumn{7}{|c|}{ Duration of employment during styrene production } \\
\hline$<5$ years & 1.00 (reference) & 1.00 (reference) & 1.00 (reference) & 1.00 (reference) & 1.00 (reference) & 1.00 (reference) \\
\hline$\geq 5$ years & 3.72 (0.88 to 15.64$)$ & 2.50 (0.64 to 9.73$)$ & 0.67 (0.18 to 2.46$)$ & $0.96(0.26$ to 3.55$)$ & $0.33(0.04$ to 2.59$)$ & $0.24(0.03$ to 1.95$)$ \\
\hline Per year & 1.07 (0.96 to 1.19$)$ & $1.07(0.95$ to 1.20$)$ & $0.97(0.86$ to 1.10$)$ & $1.04(0.91$ to 1.19$)$ & $0.95(0.81$ to 1.12$)$ & $0.95(0.80$ to 1.14$)$ \\
\hline
\end{tabular}

* In accordance with the data confidentiality policy of Statistics Denmark, no less than four cases per cell were reported or should be inferred, and for that reason, only the overall number of cases are presented.

†Cases and controls are matched on age and sex.

$\ddagger$ Cases and controls are matched on age, sex and employment in a reinforced plastics company producing boats or in wood industry (never, ever, unknown). 
adenocarcinoma for a high cumulative styrene exposure score (OR 5.11; 95\% CI 0.58 to 45.12 , table 1). High mean styrene exposure intensity, high styrene exposure probability and long duration of employment during styrene production all showed approximately doubled risks of sinonasal adenocarcinoma. For adenocarcinoma, positive log-linear relations were seen for all styrene exposure metrics; however, none were of statistical significance. We observed a fourfold increased risk of adenocarcinoma following exposure received during the recent $<15$ years (OR 3.88; 95\% CI 0.71 to 21.05 ) and a decreased risk following more distant exposure (online Supplementary table 2). No increased risks were indicated for squamous cell carcinomas or the other histological subtype category.

\section{DISCUSSION}

We observed a fivefold non-significantly increased risk of sinonasal adenocarcinoma following a high level cumulative styrene exposure score. The increased risk was confined to exposure received during the recent 15 years. No increased risks were apparent for other histological subtypes.

To our knowledge, no other epidemiological study has evaluated the risk of sinonasal cancer following styrene exposure. Results for exposure to unspecified organic solvents, which may include styrene, have been inconsistent. Animal studies have shown increased occurrence of lung tumours in mice exposed to styrene. ${ }^{10}$ Styrene is metabolised to styrene-7,8-oxide, which has genotoxic effects through formation of DNA adducts and singlestrand breaks and this could indicate mutagen-initiated carcinogenesis. ${ }^{8}$ A cytotoxic effect of styrene has also been suggested, and regenerative hyperplasia has been shown in respiratory tissues. ${ }^{10}$ The exclusive association with recent styrene exposure is more suggestive of a promoter than an initiator effect and differs from that seen for wood dust showing a latency period of about 20 years. $^{2}$ The exclusive association seen for adenocarcinomas suggests this histological subtype to be more susceptible to environmental exposures.

Information on outcome and exposure relied on sources independent of the participants and misclassification of exposure and outcome are expected to be non-differential and unlikely to explain our findings. Furthermore, our grouping of exposure should mainly lead to Berkson type error causing little or no bias of the exposure response relation. Due to high coverage of the registries, a public healthcare system in Denmark with no user payment, recruitment and follow-up were almost complete.

Four of the nine cases of andenocarcinoma were employed in a reinforced plastics company producing boats and potentially wood dust exposed, for example, during manufacturing of interior fitting or employed in other wood industry at some point in time since 1964. Matching controls on this information should have reduced confounding from such exposure even if this took place more than 20 years earlier since the first case of adenocarcinoma occurred in the 1990s. But residual confounding cannot be ruled out due to the limited information on wood dust exposure, for example, related to production of wooden moulds within the industry.

Nickel, leather dust and formaldehyde are other documented or suspected risk factors for sinonasal cancer but they are not expected to be present in the reinforced plastics industry. ${ }^{311}$ Tobacco smoking is associated with sinonasal squamous cell carcinoma but shows weak and inconsistent association with adenocarcinoma. ${ }^{12}$
Sinonasal adenocarcinoma is a rare disease and despite the large population and the more than 1.5 million accumulated person-years, the small number of cases is a limitation as reflected by the wide CIs. But the rarity of the disease may also be a strength because it is expected to reflect rare causes and thus the potential for large effect estimates. ${ }^{6}$

In conclusion, this study suggests an increased risk of sinonasal adenocarcinoma following styrene exposure. The observations are, however, few, confounding from wood dust exposure cannot be ruled out, and additional studies are needed before firm conclusions can be drawn.

Contributors MSN conducted analysis and interpretation of data and drafted the work. All authors designed the work, interpreted data, revised it for intellectual content and provided final approval for the work to be published and agreed to be accountable for all aspects of the work.

Funding The study is funded by the Danish Council for Independent Research (grant no. 6110-00197) and the Danish Working Environment Research Fund (grant no. 32-2011-09).

Competing interests None declared.

Patient consent Not required.

Ethics approval The Danish Data Protection Agency approved the study (j.no: 1-16-02-01-07). In Denmark, register studies and individual surveys, where biological materials are not included, do not need approval from the Committee System on Biomedical Research Ethics. Participants in the survey were informed of the possibility to withdraw their consent of participation at any point in time.

Provenance and peer review Not commissioned; externally peer reviewed.

Open Access This is an Open Access article distributed in accordance with the Creative Commons Attribution Non Commercial (CC BY-NC 4.0) license, which permits others to distribute, remix, adapt, build upon this work non-commercially, and license their derivative works on different terms, provided the original work is properly cited and the use is non-commercial. See: http://creativecommons.org/ licenses/by-nc/4.0/

(C) Article author(s) (or their employer(s) unless otherwise stated in the text of the article) 2018. All rights reserved. No commercial use is permitted unless otherwise expressly granted.

\section{REFERENCES}

1 Acheson ED, Cowdell RH, Hadfield E, et al. Nasal cancer in woodworkers in the furniture industry. Br Med J 1968;2:587-96.

2 Demers PA, Kogevinas M, Boffetta P, et al. Wood dust and sino-nasal cancer: pooled reanalysis of twelve case-control studies. Am J Ind Med 1995;28:151-66.

3 IARC Working Group on the Evaluation of Carcinogenic Risks to Humans. Arsenic, metals, fibres, and dusts. IARC Monogr Eval Carcinog Risks Hum 2012;100(Pt C):11-465.

4 Waldron HA. A brief history of scrotal cancer. Br J Ind Med 1983;40:390-401.

5 Creech JL, Johnson MN. Angiosarcoma of liver in the manufacture of polyvinyl chloride. J Occup Med 1974;16:150-1.

6 Rothman KJ. Causes. Am J Epidemiol 1976;104:587-92.

7 Christensen MS, Hansen J, Ramlau-Hansen $\mathrm{CH}_{\text {, et al. Cancer incidence in workers }}$ exposed to styrene in the Danish-reinforced plastics industry, 1968-2012. Epidemiology 2017;28:300-10.

8 IARC Working Group on the Evaluation of Carcinogenic Risks to Humans. Some traditional herbal medicines, some mycotoxins, naphthalene and styrene. IARC Monogr Eval Carcinog Risks Hum 2002:82:1-556.

9 Christensen MS, Vestergaard JM, d'Amore F, et al. Styrene exposure and risk of lymphohematopoietic malignancies in 73,036 reinforced plastics workers. Epidemiology. In Press.

10 National Academy of Sciences. Committee to review the styrene assessment in the national toxicology program 12th report on carcinogens, board on environmental studies and toxicology, division on earth and life studies, national research council. Washington (DC): National Academy of Sciences, 2014.

11 IARC Working Group on the Evaluation of Carcinogenic Risks to Humans. Chemical agents and related occupations. IARC Monogr Eval Carcinog Risks Hum 2012;100(Pt F):9-562.

12 't Mannetje A, Kogevinas M, Luce D, et al. Sinonasal cancer, occupation, and tobacco smoking in European women and men. Am J Ind Med 1999;36:101-7. 